Journal of Scientific Perspectives

\author{
Volume 3, Issue 3, Year 2019, pp. 177-188 \\ E - ISSN: 2587-3008 \\ URL: http://ratingacademy.com.tr/ojs/index.php/jsp \\ DOİ: https://doi.org/10.26900/jsp.3.018 \\ Research Article
}

\title{
EXPERIMENTAL SETUP FOR AC MOTOR SPEED CONTROL BY USING PLC
}

\author{
Mehmet Can DEMİ * \& Cengiz TEPE ** \& İlyas EMINOĞLU *** \\ * Graduate Student, Ondokuz Mayls University, TURKEY, \\ e-mail:mehmetcan-demir@hotmail.com \\ ORCID: https://orcid.org/0000-0002-2372-4242 \\ ** Assist. Prof. Dr., Ondokuz Mayls University, TURKEY, \\ e-mail: cengiztepe1@gmail.com \\ ORCID ID: https://orcid.org/0000-0003-4065-5207 \\ *** Assist. Prof. Dr., Ondokuz Mayls University, TURKEY, \\ e-mail: ilyaseminoglu@hotmail.com \\ ORCID ID: https://orcid.org/0000-0003-4143-1395
}

Received: 10 July 2019; Accepted: 25 July 2019

\section{ABSTRACT}

PLC is widely used in industrial control application. For this reason, PLC education has an important place in the content of universities and it is explained in different engineering department.

In this paper, AC motor speed control by using PLC experimental setup is designed and implemented. Through this experimental setup, students can experience and use of the encoder, 3-phase AC motor and PID control algorithm. Besides, this experimental setup helps students to develop their real time engineering skill and experience in departments of universities such as electrical-electronics, mechatronics, control and automation engineering.

Keywords: PLC, PID Control, AC Motor Speed Control, Encoder, Inverter 


\section{INTRODUCTION}

PLC is an integrated device with programming support that assigns inputs to the output after one or more operations such as logic, data processing, counting, database, arithmetic. PLCs can be used in sequential control, motion control, process control or data management.PLC architecture includes three conceptual layers: hardware, firmware and programmable area(1-3).

PLC programming can be done in three different ways: Ladder diagram, STL (Statement List Editor), FBD (Function Block Diagram). The ladder diagram is a programming language based on electrical circuits. FBD is a graphical language used to tell signal and data flow through function blocks. STL is a programming language, which is realized by writing code, similar to the language $C(4,5)$.

Complex automation problems can be solved quickly and easily through PLCs. Compared to other control methods, PLCs are less damaged, more reliable, easier to maintain, more resistant the environmental conditions and have many advantages. Because of all these advantages, they are often preferred in industry.

In the Electrical and Electronic Engineering Department of the Ondokuz Mayis University (OMU) (Samsun/ Turkey), PLC is introduced in the Introduction to Industrial Control Systems lesson. In this lesson content, there are PLC types such as Siemens S7-1200, ABB500, Delta, Mitsubishi. This study was carried out using Siemens S7-1200. This experimental setup was carried out as a project assignment in the advanced PLC lesson at the OMU Institute of Science Electrical and Electronic Engineering graduate program. For the last two semesters, it has been used as an experimental setup in the Electrical and Electronic Engineering undergraduate laboratory.

PID control is a control method commonly used in motor speed adjustment or other 178 control systems $(6,7)$. In this study, PID control was performed using PLC and the motor speed was adjusted to desired speed.

The purpose of this study is to provide an experimental setup for undergraduate and graduate students to learn the use of PID block using PLC. In addition, students performing this experiment have an idea to solve other control problems.

\section{PID CONTROL}

PID control is a control method comprising proportional, integral and derivative elements. Each element has a coefficient and these coefficients are processed the certain mathematical operations with the error signal. The coefficient of the proportional element is multiplied by the error signal, the coefficient of the integral element is multiplied by the integral of the error signal , and the coefficient of the derivative element is multiplied by the derivative of the error signal. Each result is collected and the result is the control signal $(8,9)$. The error signal is equal to the difference between the set point and the input. The equation that expresses all of this is as follows:

$$
u(t)=K_{p} e(t)+K_{i} \int e(t) d t+K_{d} \frac{d}{d t} e(t)
$$

\subsection{Properties of Proportional, Integral and Derivative Elements}

Each PID element acts differently to the operation of the control system. The proportional element reduces the rise time. The integral element greatly decrease the steadystate error. The derivative element provides reduction of overshoot(10). In Table 1, it is shown the effect of each of the PID parameters on the system(11). 
Table 1: Effects of PID Parameters

\begin{tabular}{|l|l|l|l|l|}
\hline PID Parameters & Rise Time & Overshoot & Settling Time & Steady-State Error \\
\hline Proportional & Decrease & Increase & Small Increase & Decrease \\
\hline Integral & Small Decrease & Increase & Increase & Large Decrease \\
\hline Derivative & Minor Change & Decrease & Decrease & Minor Change \\
\hline
\end{tabular}

3. THE EXPERIMENTAL SETUP

Figure 1: The Experimental Setup

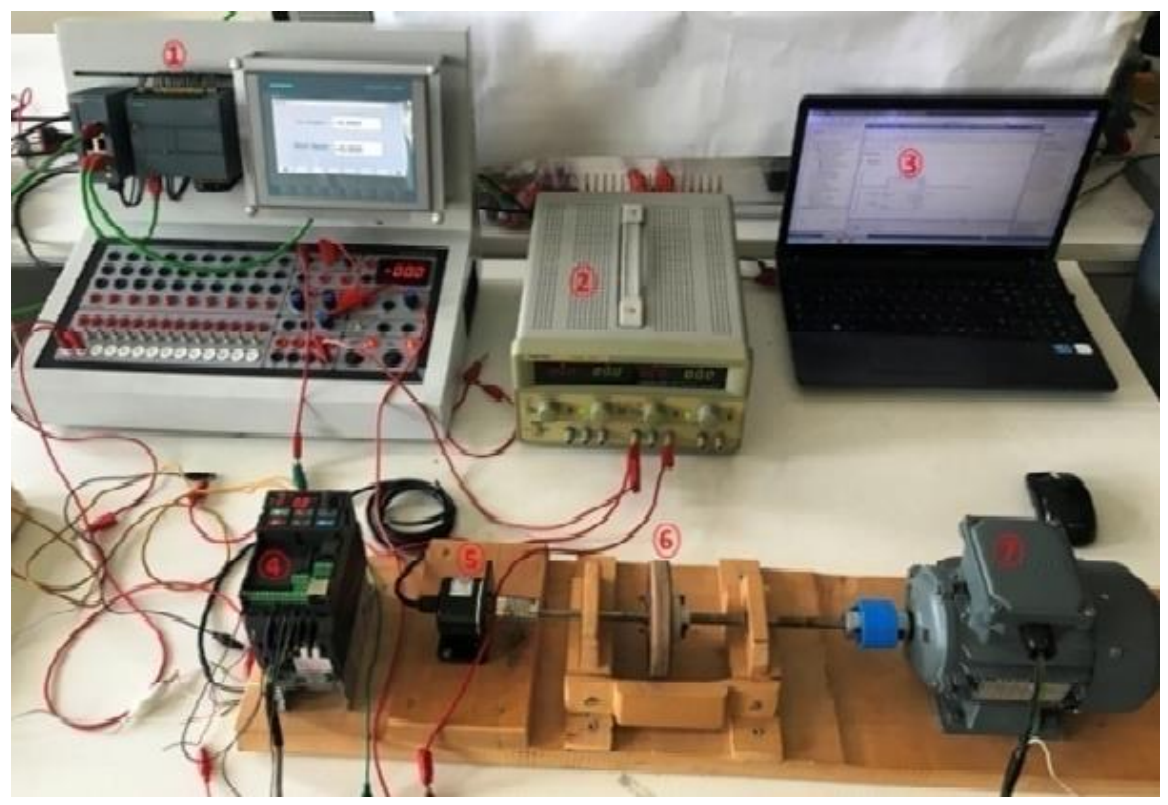

The experimental setup for this study is shown in Figure 1. This experimental setup consists of seven parts.

Part 1 is PLC experiment set. On this experiment set; there are communication module, PLC (Siemens S7-1200), HMI (KTP 700 Basic PN), digital inputs, LEDs indicating digital output, relays, analog input and output, 20-pulse encoder, $24 \mathrm{~V}$ supply and ground connections and voltmeter.

Part 2 is the DC power supply. $24 \mathrm{~V}$ supply of the encoder is provided here.

Part 3 is the computer platform. PLC program is written in computer platform and loaded to PLC through ethernet cable.

Part 4 is the inverter. 0-10 V voltage is received from the analog output of the PLC and this voltage is transmitted to the inverter. According to the this voltage information sent to it, the inverter drives the motor by sending energy to the motor at the required frequency.

Part 5 is the encoder. The encoder connected to the motor shaft generates a certain number of pulses per turn. The motor speed is calculated by evaluating the number of pulses produced by the PLC.

Part 6 is the part to be applied to the disturbance.

Part 7 is the AC motor to be controlled. 
Figure 2: The Experimental Setup Control Block Diagram

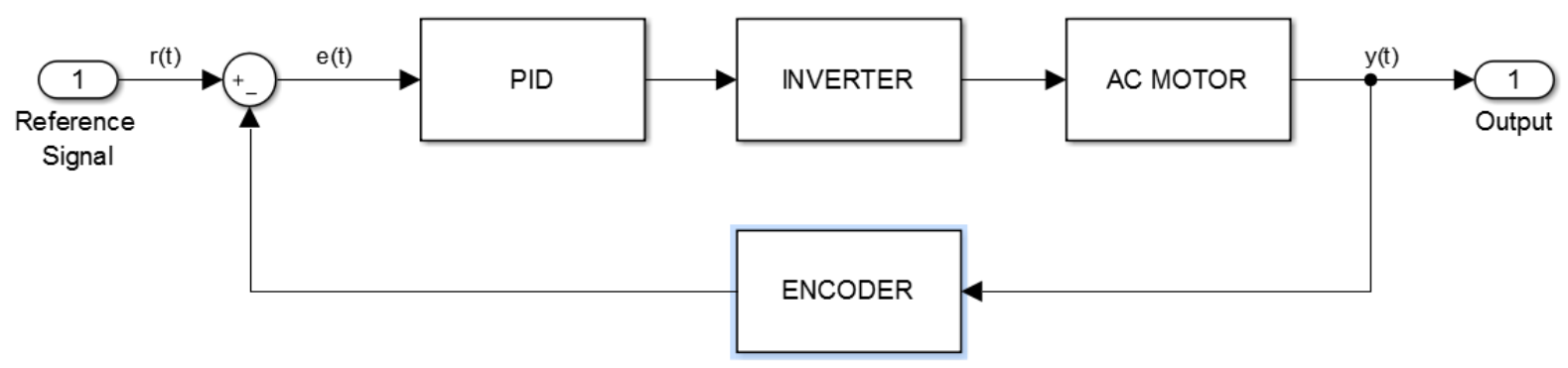

\subsection{Programmable Logic Controller (PLC) and Human-Machine Interface (HMI)}

In this study, Siemens S7-1200 1214C DC/DC/DC(12) type PLC is used. Here DC/DC/DC refers to the operation of the PLC. The first DC indicates that the PLC is supplied with $24 \mathrm{~V} \mathrm{DC}$ voltage. The second DC indicates that the input signals are $24 \mathrm{~V} \mathrm{DC}$ voltage. The third DC indicates that the PLC has a transistor output.

In the PLC used in this study, there are 6 high-speed counters (HSC), 2 analog inputs, 14 digital inputs and 10 digital outputs. Furthermore, an analog output board is added, giving 1 analog output.

In order to enter the set point and see the motor speed, a touch screen called HMI is designed. The indicators to be used are taken from the elements tab and the necessary addresses are defined for each. As a result, the design in Figure 3 has emerged.

Figure 3: HMI Design

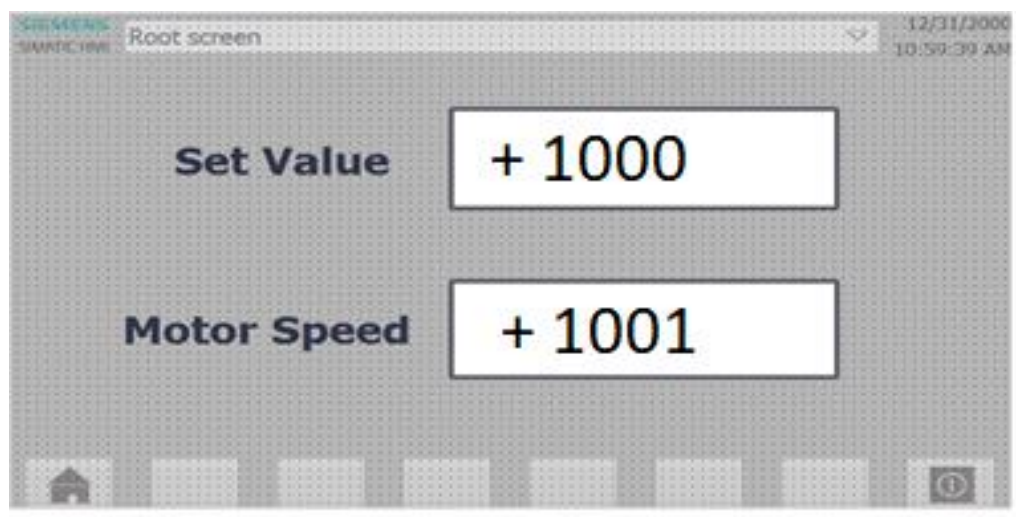

\subsection{Inverter}

Devices that drive the AC motor at different speeds by changing the frequency of energy from the grid are called inverters. The inverter used in this study(13) is shown in Figure 4. The inverter used has a single phase supply, so the inputs L1 and L2 are used when feeding. The inverter output from the $\mathrm{U}, \mathrm{V}, \mathrm{W}$ terminals is connected to the $\mathrm{AC}$ motor. The analog output from the PLC is connected to the AVI terminal and the common end of the analog output is connected to the ACM terminal. All of these connections are shown in Figure 5. 
Figure 4: Used Inverter

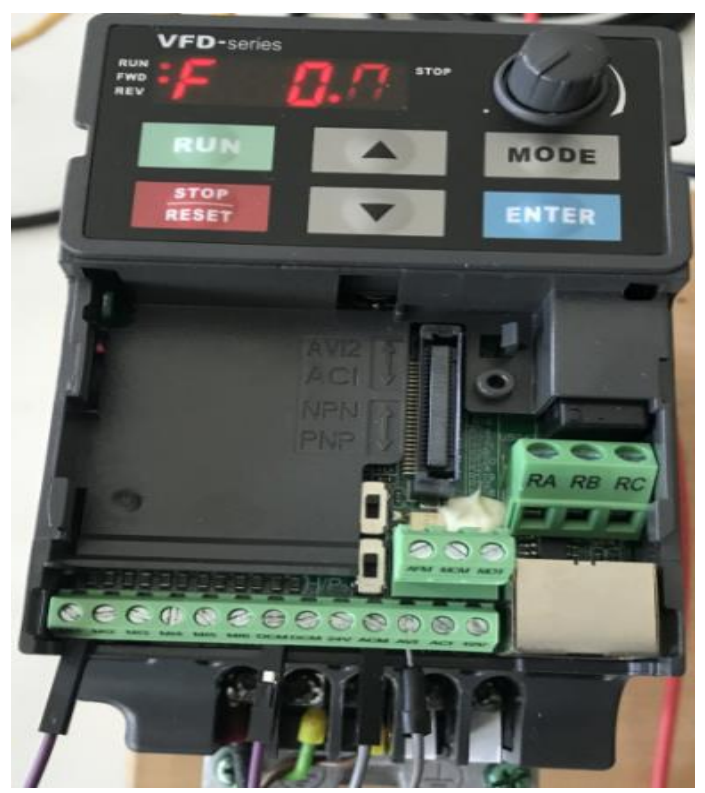

Figure 5: Inverter Connections

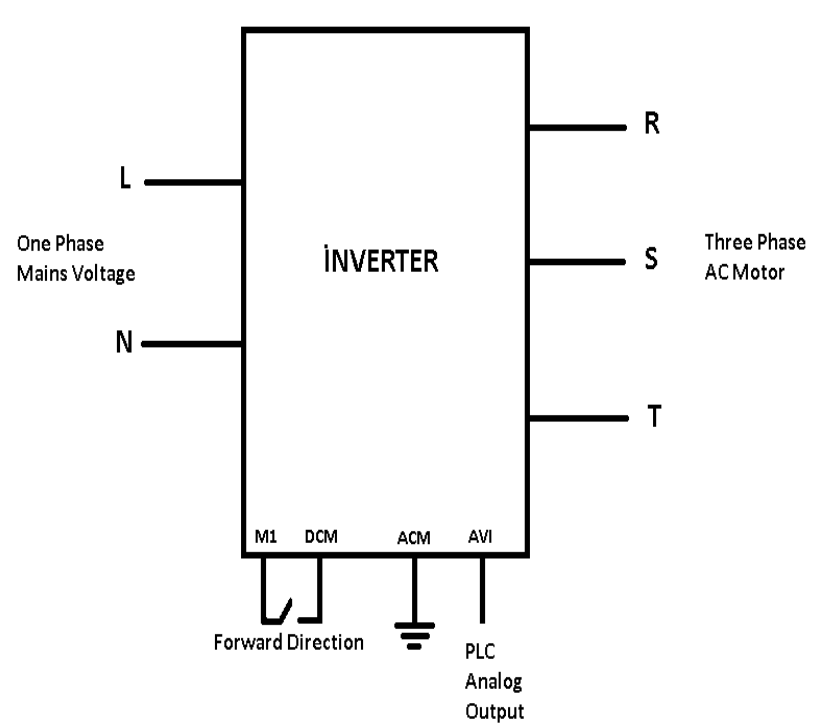

\subsection{Encoder}

In this study, incremental rotary encoder(14) is used and it produces 2500 pulses per turn. The incremental encoder means that when the power is cut off, the information inside it will be reset. The rotary encoder means that it will produce a certain number of pulses when the shaft is turned. Rotary encoders produce pulses from two separate outputs called phase A and phase B. These pulses produced from phase A and B have a phase difference of 90 degrees. In order to observe these pulses and phase difference, $\mathrm{A}$ and $\mathrm{B}$ phases of the encoder were examined through an oscilloscope and the imagine in Figure 6 was obtained. In this figure, the pulses and phase difference are clearly seen.

Figure 6: Oscilloscope image of phases A and B

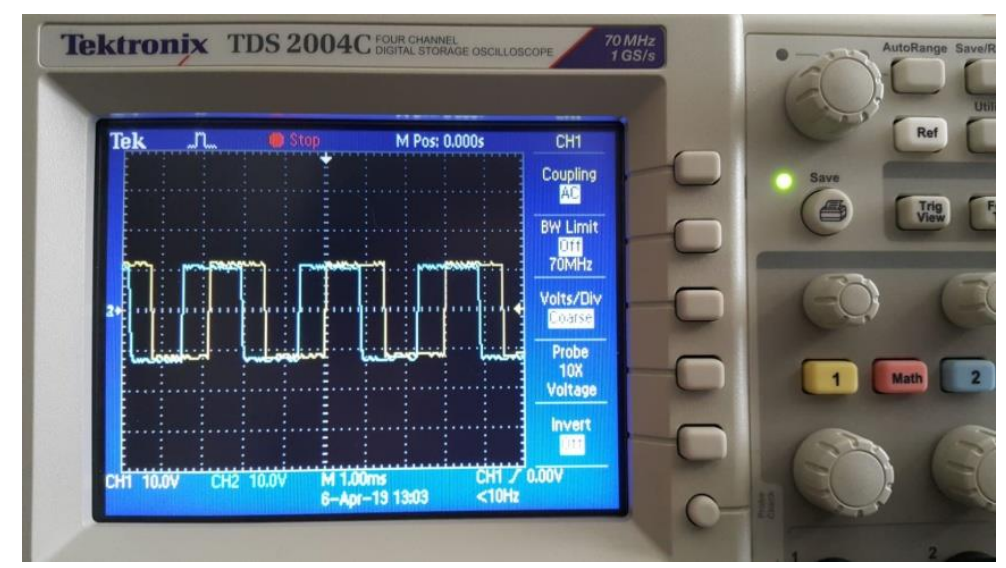

The connection of the encoder with the PLC is shown in Figure 7. The brown cable on the encoder is connected to the $24 \mathrm{~V}$ supply. The blue cable is connected to the ground. The black cable refers to phase A and it is connected to the I0.0 input of the PLC. The white cable refers to phase B and it is connected to the I0.1 input of the PLC. 
Figure 7: Connections of PLC to Encoder and Inverter

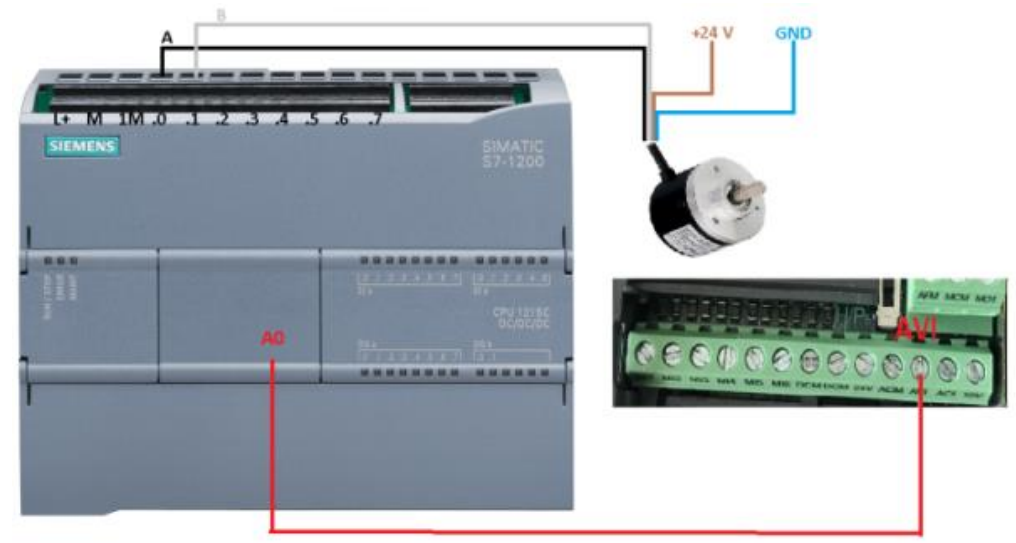

\subsection{AC Motor}

The AC Motor used in this study(15) and the disturbance disc are shown in Figure 8. The characteristics of this AC motor are as follows:

Figure 8: AC Motor and Disturbance Disc

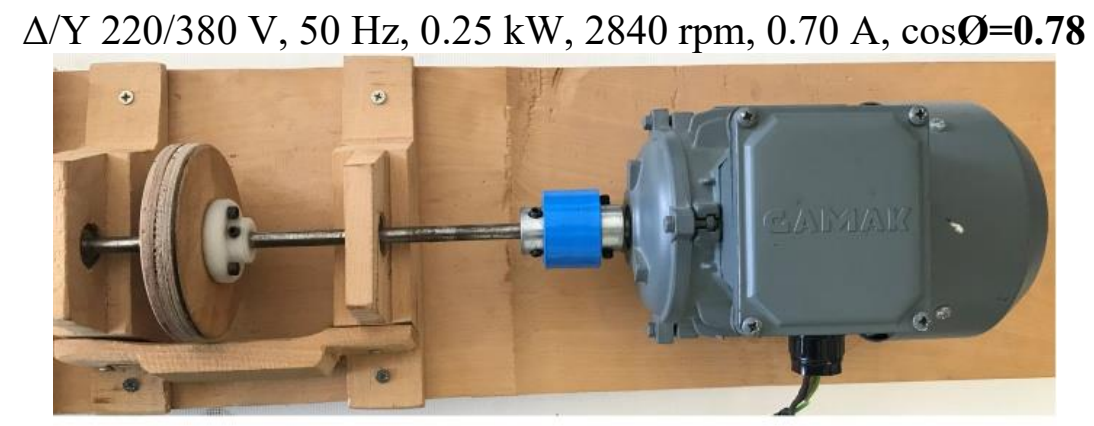

\subsection{PLC Program}

\subsubsection{Main Block Program}

Figure 9: Main Block Network 1

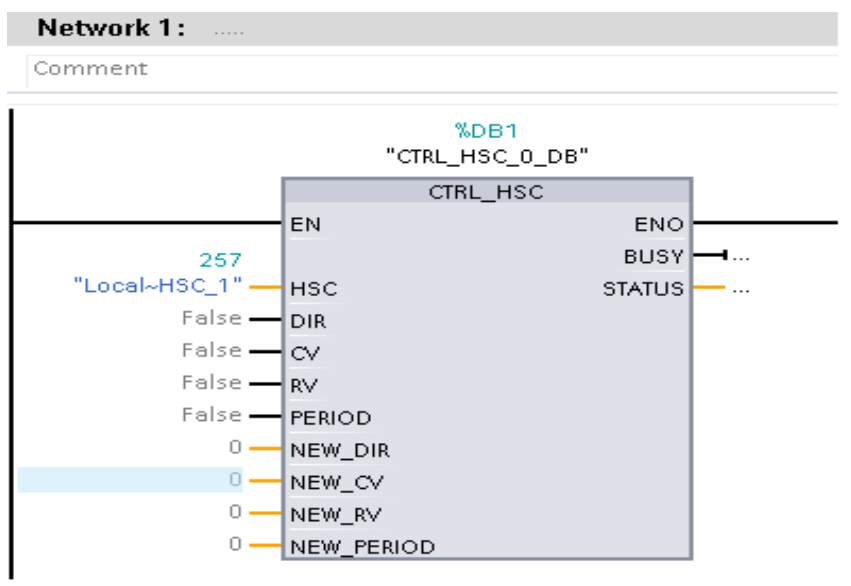


Figure 10: Main Block Network 2

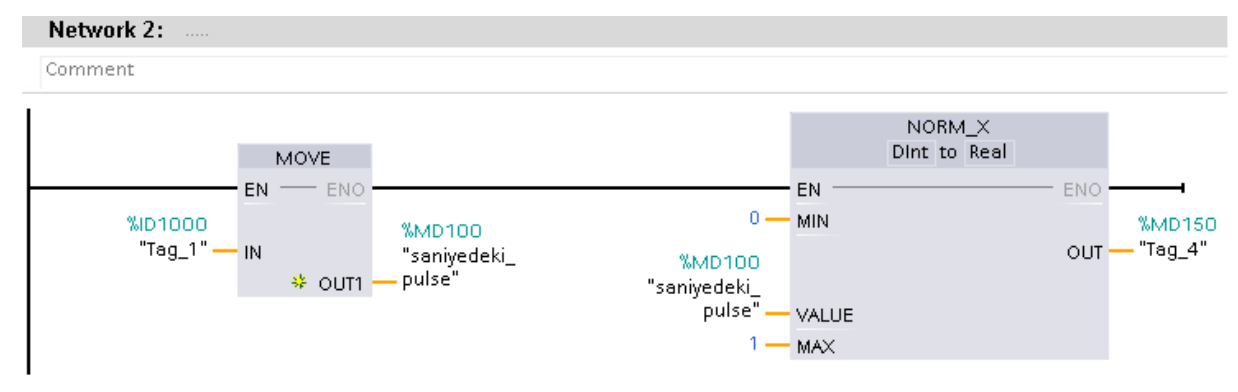

Figure 11: Main Block Network 3

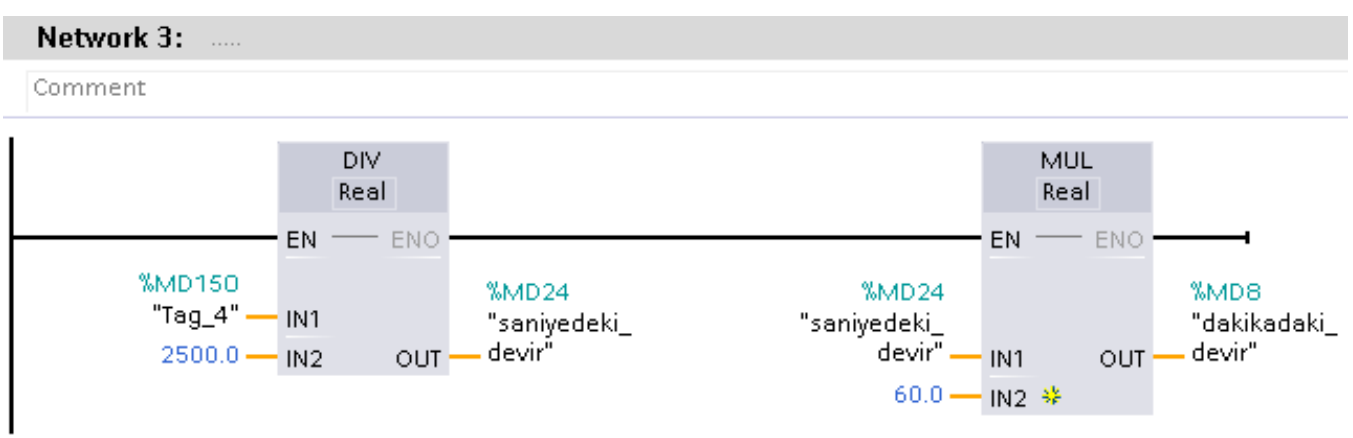

The main block program consists of 3 networks and is shown in Figure 9-10-11. The network 1 shown in Figure 9 is a High Speed Counter (HSC) block. The counting of the pulses taken from the encoder is done here. In the network 2 shown in Figure 10, the information HSC reads assigned to an address and converted to a real number. Information indicating the number of pulses per second read from ID1000 address by HSC block is assigned to MD100 address through the MOVE block. In order for speed measurement to be done correctly, the information at MD100 address is converted to real number and assigned to the MD150 address through the NORM_X block. In the network 3 shown in Figure 11, the information indicating the number of pulses per second defined at MD150 address is converted to rpm as a result of certain mathematical operation. The information at MD150 address is divided by 2500 (the number of pulses produced by encoder per turn) through DIV block. As a result of this operation, revolutions per second is obtained. Then this information is multiplied by 60 to obtain revolutions per minute (rpm) through MUL block and the operation result is assigned at MD8 address. Thus the motor speed is measured and read from MD8.

\subsubsection{Cyclic Interrupt Program}

Figure 12: PID Block

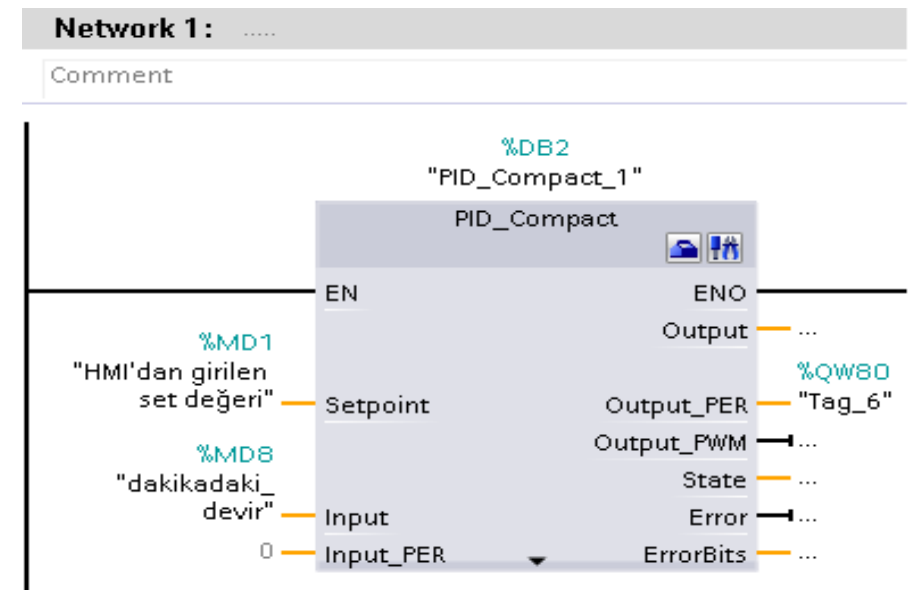


The PID block is not written into the main block. It is written into the cyclic interrupt created separately from the main block. After the PID block has been added, the motor speed information stored into the MD8 address is written to the input of the PID block. Set point information that is defined MD1 address when designing HMI is written to "Setpoint" section of PID block. For PID output, the QW80 address is written to "Output_PER" section of PID block. This address is the address of the analog output board. The PID block is seen in Figure 12.

\subsubsection{PID Settings}

Click "Configurations" on the PID block to make PID settings. The pop-up window is the "Controller Type" tab, where "speed" is selected. Then "Input" and "Output_PER (Analog)" are selected in the "Input / output parameters" tab.If "Enable manual entry" is selected in the "PID parameters" tab, PID parameters can be entered manually.when the motor speed limiting is desired, lower and upper speed limits can be selected from the "Process value limits" tab. In this study, PID parameters was selected $\mathrm{Kp}=0.02, \mathrm{Ki}=3, \mathrm{Kd}=0$.

Table 2: Some PLC Addresses and Their Equivalents

\begin{tabular}{ll}
\hline PLC Address & Its Equivalent \\
\hline Fixed Addresses & \\
ID1000 & HSC1 counting address \\
QW80 & Analog output address \\
I0.0 & HSC1 digital input (phase A) \\
I0.1 & HSC1 digital input (phase B) \\
User-Selected Addresses & \\
MD1 & Set point entered from HMI \\
MD8 & Revolutions per minute (rpm) \\
MD24 & Revolutions per second \\
MD100 & Pulses per second (integer) \\
MD150 & Pulses per second (real number) \\
\hline Total Number of Addresses Used & $\mathbf{9}$ \\
\hline
\end{tabular}

\subsection{Experimental Results}

Figure 13: Operation of the motor at 1000-1200-1300 rpm

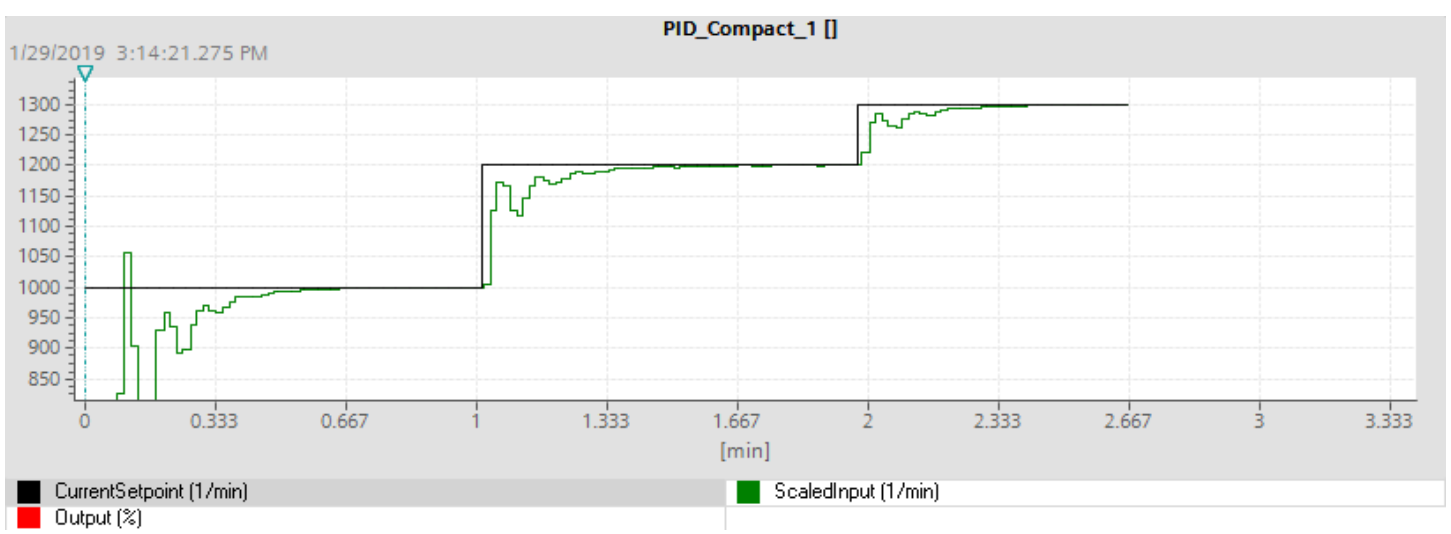


Figure 14: Graph of Disturbance

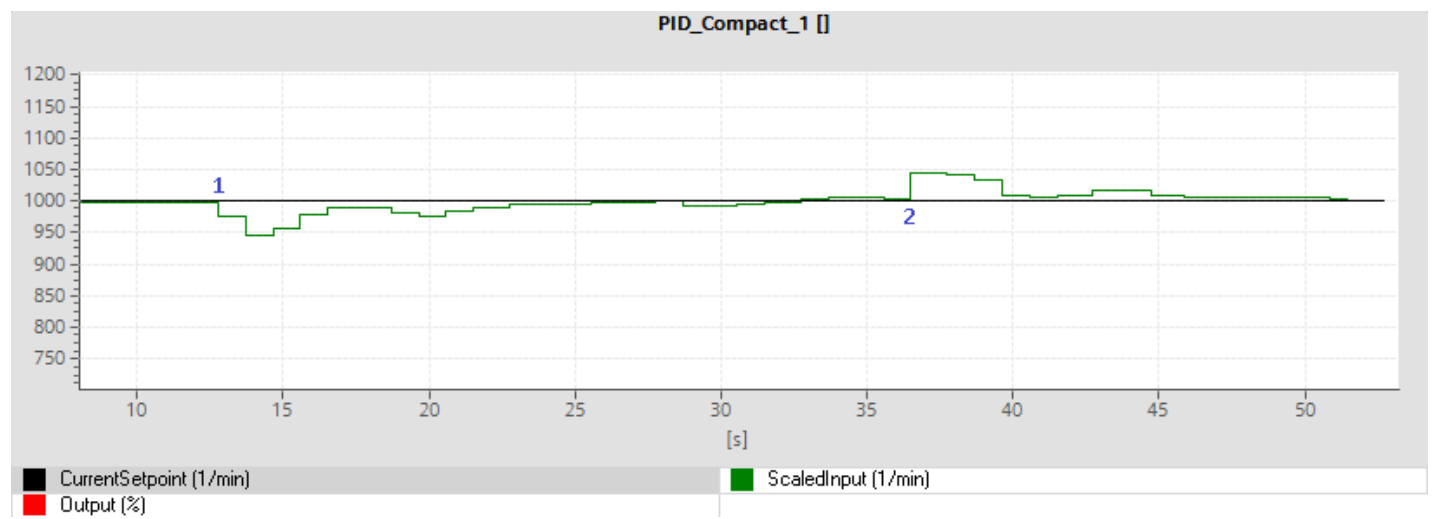

The AC motor was driven at 1000-1200-1300 rpm and graph shown in Figure 13 was obtained. In this graph, when the motor is first started or set point is changed, it is seen that the motor speed has reached the set point, after it has fluctuated below the set point for a period of time. Subsequently, the disturbance was applied while the motor was rotating at $1000 \mathrm{rpm}$. As a result of this process obtained graph is shown in Figure 14. The moment when the disturbance is applied in the graph is "1" and the moment when the disturbance is removed in the graph is "2". It was found that when the disturbance was applied, the motor speed decreased and the voltage at the analog output of the PLC increased. Then, the motor speed has reached the set point again. When the disturbance is removed, the motor speed has reached the set point again after exceeding the set point for a moment. In addition, some data obtained by driving the motor at different speeds were recorded. These data are shown in Table 3 Figure 15 shows how the settling time and error change for some motor speed values. As seen in the graph, when the motor speed increased, the error decreases, but the settling time increases.

Table 3: Some data obtained by motor speeds

\begin{tabular}{|c|c|c|c|c|}
\hline $\begin{array}{c}\text { Motor Speed } \\
(\mathbf{r p m})\end{array}$ & $\begin{array}{c}\text { Settling Time } \\
(\mathbf{s})\end{array}$ & $\begin{array}{c}\text { Error } \\
(\mathbf{r p m})\end{array}$ & $\begin{array}{c}\text { Analog Output } \\
\text { Without } \\
\text { Disturbance } \\
(\mathbf{V})\end{array}$ & $\begin{array}{c}\text { Analog Output } \\
\text { With } \\
\text { Disturbance } \\
(\mathbf{V})\end{array}$ \\
\hline 200 & 42 & 4 & 0.75 & 0.93 \\
\hline $\mathbf{3 0 0}$ & 49 & 1 & 1.08 & 1.35 \\
\hline $\mathbf{4 0 0}$ & 41 & 2 & 1.40 & 1.58 \\
\hline $\mathbf{5 0 0}$ & 42 & 1 & 1.73 & 1.94 \\
\hline $\mathbf{7 0 0}$ & 48 & 1 & 2.40 & 2.52 \\
\hline $\mathbf{8 0 0}$ & 58 & 1 & 2.74 & 2.90 \\
\hline $\mathbf{9 0 0}$ & 66 & 1 & 3.07 & 3.29 \\
\hline $\mathbf{1 0 0 0}$ & 57 & 0.5 & 3.40 & 3.58 \\
\hline $\mathbf{1 2 0 0}$ & 56 & 0.5 & 4.06 & 4.25 \\
\hline $\mathbf{1 3 0 0}$ & 68 & 0.5 & 4.40 & 4.60 \\
\hline
\end{tabular}


Figure 15: Graph of Settling Time-Motor Speed-Error

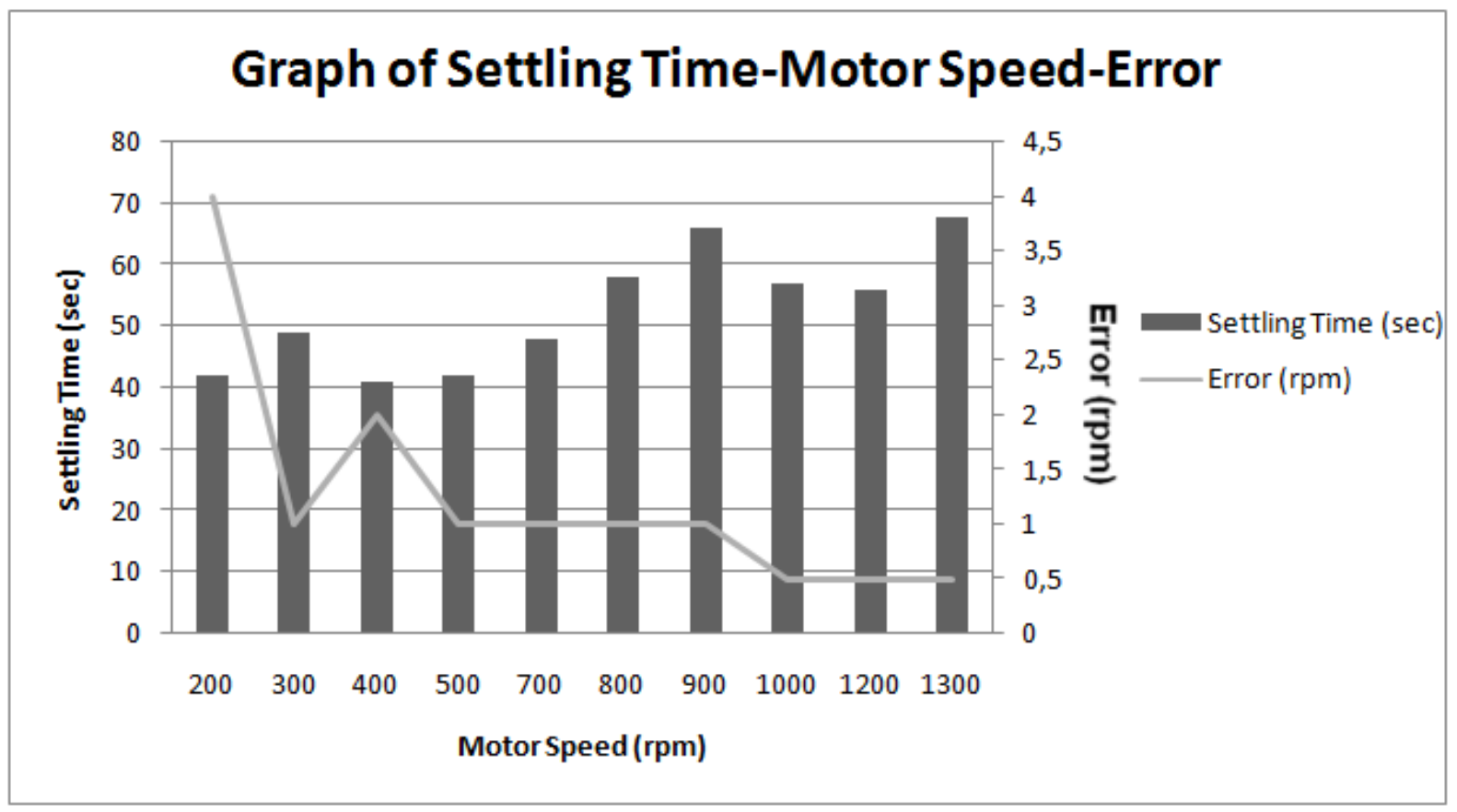

In this study, encoders of two different brands were tested. Firstly, 600 pulse encoder was preferred due to its low cost. However, the pulses produced by this encoder are $5 \mathrm{~V}$ in PLC, not $24 \mathrm{~V}$. Therefore, the counting with the HSC inputs of the PLC could not be performed. This problem has been fixed by stabilizing the encoder outputs to $24 \mathrm{~V}$ over the buffer. Secondly, Autonics brand 2500 pulse encoder was tested. Since there was no voltage drop problem in this encoder, the study was performed with this encoder.

\section{OBSERVATIONS AND RESPONSES}

This experiment was applied to 29 students in the fourth year of Electrical-Electronics Engineering in Ondokuz Mayis University (Samsun/Turkey) in 2019. These students are divided into 6 groups. Firstly, software (PLC ladder diagram) and hardware (inverter, AC motor, encoder) parts of AC motor speed control test are explained in detail. Then, the experimental setup for the AC motor speed control was established and the working mechanism was shown to the students. During the application phase, the students were able to assimilate the subject with the question-answer method. Each student group conducted the experiment under the guidance of instructor.

Most group have successfully completed the experiment. At the end of the experiment, students' observations and responses were recorded using the interview form. The students were asked 4 questions, "strongly agree", "agree", "disagree", "strongly disagree".

According to the Table 4, 100\% of students found this project useful and educational. The reason why they find it useful and educational is that the issue involves a direct industrial practice. Students have firstly tested speed control of AC motor with PLC. The speed control of the AC motor with PLC through the HMI display has aroused the curiosity and excitement of the students.

$100 \%$ of the students stated that they understand how PLC works. The students experienced the theoretical knowledge they received in the lessons. They have been informed about PLC power connections, input and output units, inverter, encoder and AC motor connections and their working principles. This practice is important for learning where and how 
to use the information. At the same time, it was observed that the self-confidence of the students who could apply the knowledge they learned increased.

93.1\% of the students stated that they had learned to use encoder and inverter with PLC. As a result of interviews with the some students, it was seen that the students learned to PLC programming, use PID block, read encoder, drive inverter, control AC motor and obtain control signal. According to the results of the study, $96,55 \%$ of the students stated that they understand the speed control of the AC motor by using PLC.

Table 4: Evaluation of observations and responses

\begin{tabular}{|l|l|l|l|l|}
\hline & IV & III & II & I \\
\hline 1- I found this project useful and educational & $\% 62.52$ & $\% 34.48$ & $\% 0$ & $\% 0$ \\
\hline 2- I understand how the PLC works. & $\% 27.59$ & $\% 72.41$ & $\% 0$ & $\% 0$ \\
\hline 3- I learned the use of inverter and encoder as well as PLC. & $\% 31.03$ & $\% 62.07$ & $\% 6.9$ & $\% 0$ \\
\hline $\begin{array}{l}\text { 4- I understand how to control the speed of an asynchronous } \\
\text { motor using PLC. }\end{array}$ & $\% 37.93$ & $\% 58.62$ & $\% 3.45$ & $\% 0$ \\
\hline IV: I strongly agree III: I agree II: I disagree & I: I strongly disagree \\
\hline
\end{tabular}

\section{CONCLUSION}

In factories, industrial control systems are used in many fields such as pressure, temperature, motor speed control etc. PLC is the most preferred among them. Therefore, PLC courses are taught in different engineering departments of universities. In addition to theoretical knowledge, it should be shown in industrial applications in PLC education. For this reason, in this study, the AC motor speed control experimental setup is designed. Encoder as an input sensor, inverter as the actuator, PLC as the controller are used. Through this experimental setup, the students assigned the encoder as the input of the PLC, the inverter was assigned as the output of the PLC and programmed. They have also learned to use the PID block in the PLC and can use the PID block in other industrial control applications such as pressure and temperature. Thanks to this study, the students experienced the operation of an industrial control system in real time.

After students have learned the PLC, they can take this study as a finishing project and they can make some changes on it and use it as an experimental setup in their own laboratories. For instance; tachometer instead of encoder, other model PLCs instead of Siemens S7-1200, DC motor instead of AC motor, DC motor driver (LD298 or H-Bridge Driver) instead of inverter.

This experimental setup can be used in the Control Laboratories of the departments of Electrical-Electronic, Mechatronics, Control and Automation Engineering. 


\section{REFERENCES}

[1] Özerdem ÖC. Design of two experimental setups for programmable logic controller (PLC) laboratory. International Journal of Electrical Engineering Education. 2016;53(4):33140 .

[2] Manesis S, Koutri S. A student-friendly approach to undergraduate teaching of experimental industrial control systems. International Journal of Electrical Engineering Education. 2003;40(4):255-69.

[3] Geaney G, O’Mahony T. Design and evaluation of a remote PLC laboratory. International Journal of Electrical Engineering Education. 2016;53(3):212-23.

[4] Berger H. Automating with STEP7 in STL and SCL: programmable controllers Simatic S7300/400: Publicis; 2006.

[5] Boix O, Gomis O, Montesinos D, Galceran S, Sudrià A. Comparative experiences in remote automation laboratories with real plants. International Journal of Electrical Engineering Education. 2008;45(4):310-20.

[6] Kaldate AP, Kulkarni SA. PLC Based PID Speed Control System. IOSR Journal Of Engineering. 2014;4.

[7] Saad N, Arrofiq M. A PLC-based modified-fuzzy controller for PWM-driven induction motor drive with constant $\mathrm{V} / \mathrm{Hz}$ ratio control. Robotics and Computer-Integrated Manufacturing. 2012;28(2):95-112.

[8] Köse F, Kaplan K, Ertunç HM. PID ve bulanık mantık ile DC motorun gerçek zamanda STM32F407 tabanlı hiz kontrolü. Otomatik Kontrol Ulusal Toplantıs1, TOK2013. 2013:26-8.

[9] Basilio J, Manhães R, Rolim L. Benchmark construction with application to PID controller design and implementation. International Journal of Electrical Engineering Education. 2008;45(1):51-71.

[10] Coşkun İ, Terzioğlu H. Hız performans eğrisi kullanılarak kazanç (PID) parametrelerinin belirlenmesi. Selçuk Üniversitesi Teknik Bilimler Meslek Yüksekokulu Teknik-Online Dergi 2007;6(3):180-205.

[11] Ang KH, Chong G, Li Y. PID control system analysis, design, and technology. IEEE transactions on control systems technology. 2005;13(4):559-76.

[12] Siemens AG [05.04.2019]. Available from: https://cache.industry.siemens.com/dl/files/465/36932465/att_106119/v1/s71200_syst em_manual_en-US_en-US.pdf

[13] Delta VFD-E [05.04.2019]. Available from: http://www.inverterplc.net/delta/delta/DELTA_VFDE_SERISI_HIZ_KONTROL_CiHAZI_KULLANIM_KLAVUZU.pdf.

[14] Autonics Online Store [05.04.2019]. Available from: http://www.autonicsonline.com/image/pdf/E50S.pdf.

[15] Gamak [05.04.2019]. Available from: http://www.gamak.com. 